\title{
Enterprise Cloud Computing Project for Connecting Higher Education Institutions: A Case Study of the UAE
}

\author{
Mounir M. El Khatib ${ }^{1}$, Gouher Ahmed ${ }^{2}$, Ahmed Al-Nakeeb ${ }^{1}$ \\ ${ }^{1}$ School of Business and Quality Management, Hamdan Bin Mohammad Smart University, Dubai, UAE \\ ${ }^{2}$ School of Business Management, Skyline University College, Sharjah, UAE \\ Email: m.elkhatib@hbmsu.ac.ae, gouher@usa.net, a.alnakeeb@hbmsu.ac.ae
}

How to cite this paper: El Khatib, M.M., Ahmed, G. and Al-Nakeeb, A. (2019) Enterprise Cloud Computing Project for Connecting Higher Education Institutions: A Case Study of the UAE. Modern Econo$m y, 10,137-155$.

https://doi.org/10.4236/me.2019.101010

Received: November 27, 2018

Accepted: January 11, 2019

Published: January 14, 2019

Copyright $\odot 2019$ by author(s) and Scientific Research Publishing Inc. This work is licensed under the Creative Commons Attribution International License (CC BY 4.0).

http://creativecommons.org/licenses/by/4.0/

(c) (i) Open Access

\begin{abstract}
The new cloud computing technology is very much in the business and economic horizon, extending its horizons to non-business sectors like education. This study is a study of the need and applicability of the fast spreading business enterprises' external cloud computing technology, to the higher educational institution in the United Arab Emirates (UAE), the educational hub of the MENA region, in terms of three premier higher educational institutions-Zayed University (ZU), Higher College of Technology (HCT), and the UAE University (UAEU) for their collaboration services for better educational services. Employing the interview method to a sample of administrators, it was found that the institutions were lacking in cloud computing (CC) resulting in delays in student services, such as inter-university transfers of students. The administrators, however, were convinced of CC technology for inter-institutional collaboration. For this, it is suggested to establish a platform of cloud computing services, with required staff training and motivation for efficient and collaboration functioning of the HEIs in the UAE, which is evolving into a global educational center. As this is not the end of the problem, there is a need for further research in the problem, such as staff exchange, and research cooperation as it is a modest but worthwhile contribution to the educational dimension of cloud computing for educational efficiency.
\end{abstract}

\section{Keywords}

Enterprise Solutions, Cloud Computing, Collaborative Systems, Change Management, Project Management

\section{Introduction}

Efficiency, flexibility, agility, cost, capacity and profitability are of the concerns 
of any organizations, whichever business, such as institutions of higher learning of immense social as well as individual value. Computing is well known to have increased organizational efficiencies. Theories and practices of management often originate from the opportunities created by new technologies [1]. Cloud computing is all the rage. In its simplest terms, it means outsourcing the company's information technology (IT) needs, from all kinds of data and storage to software. All the servers and applications remain elsewhere in the Internet "cloud", but more literally in a data center or centers [2].

According to Bloom and Pierri, "Cloud computing is an IT paradigm based on remote access to a shared pool of computing resources. Putting data in the cloud' essentially means paying someone else to manage it, and then connecting to their servers via the internet to access your data when you need it. It also means you don't need to analyze these data on your own machines, but you can 'rent' them on demand." [3]. The popularity of cloud computing has exploded during the last half a decade by cutting the fixed costs of computing, avoiding the need to hire IT staff, servers, and hardware, and even the smallest firm can satisfy large and unexpected computing needs.

Many companies of various sizes are currently adopting cloud computing. As against computing, "Cloud computing" has been defined by the National Institute of Standards and Technology of (NIST) as "a model for enabling convenient, on-demand network access to a shared pool of configurable computing resources (e.g., networks, servers, storage, applications, and services) that can be rapidly provisioned and released with minimal management effort or service provider interaction" [4]. In simple words, it is a way to deliver a service produced by a company or organization, over the internet to customers.

Cloud computing is likely to be one of those opportunities sought by the cash-strapped educational establishments in these difficult times of global economy and could prove to be of immense benefit (and empowering in some situations) to them due to its flexibility and pay-as-you-go cost structure [5].

The description of "cloud" has come from the early days of the Internet. External networks of the Internet, consisting of computers, switches, cables, servers etc., that are connected together and which the user doesn't know much about are considered as a "cloud". Cloud computing (CC) can be categorized into three categories, based on the cloud services types. These categories are as follows:

\subsection{Software as a Service (SaaS)}

This is the most famous type of cloud services where the users do not need to do any type of installation or setup as the service provider does this. This type of service might include subscription. The application is created by a company or the service provider and then it is provided to the user through the Internet.

Example: Google Apps.

\subsection{Infrastructure as a Service (IaaS)}

"Involves outsourcing the equipment used to support operations, including sto- 
rage, hardware, servers and networking components" [6].

Example: Google Compute Engine.

\subsection{Platform as a Service (PaaS)}

In this form, which is being built on top of virtualized infrastructure, the operating system and its related services "the platform" is delivered by the company to the user over the internet.

Example: Google Application Engine.

Furthermore, cloud computing can also be categorized based on the location of the cloud, as follows:

\subsection{Public Cloud}

Where the customer has no visibility over the infrastructure being provided by the cloud vendor who hosts the public cloud. Many organizations might share the same infrastructure hosted by the cloud provider.

\subsection{Private Cloud}

Where the infrastructure dedicated for the organization is exclusively used by this particular organization and not shared by others. They are more expensive than the public clouds as it is considered more secured since it is not being shared. It is also categorized into two types:

1) On-premise clouds: The infrastructure of the cloud is hosted internally in the organization.

2) Externally hosted private clouds: The Computing infrastructure is hosted in a cloud vendor or a third party.

\subsection{Hybrid Cloud}

This is a combination of both of the previous two types of the clouds (Public and Private) as the organization might place the critical application on a private cloud and the less critical ones on a public cloud.

\section{The Advantages of Cloud Computing}

The evolving technology of cloud computing, which has been a dream for many organizations, is now a reality which is being embraced progressively by organizations all around the world [7]. Just like most new technologies, cloud computing has many advantages that enable users to develop their infrastructure and systems. The Gartner Group (2013), had foreseen the 2016 year as a defining year for CC as private cloud, were expected give way to hybrid clouds, and nearly a half of large enterprises would have hybrid cloud deployments by the end of 2017, because of their advantages.

\subsection{Cost Efficiency}

Companies and organizations had suffered for a long time in expenditures spent 
on purchasing software and maintenance of software as well as hardware, in additions to the licensing fees which consumed a lot of the companies' budgets. Nowadays, cloud computing provides the same requirements to the organizations needs but at much cheaper prices.

With cloud computing, the organizations need not worry about the traditional in-house storage or backup recovery of data as the service provider or vendor is the one who takes care of this part. Efficiency increases in case of cloud solutions. In addition, organizations save a lot of manpower which consumes a large portion of the organization's budget in order to manage the software and the hardware.

\subsection{Ease of Access and Deployment of Information}

Geographic location is not an issue as cloud computing solution provides an access to the information anywhere in the world as long as there is access to the Internet.

\subsection{Flexibility}

Based on the organization's requirements, you can scale up or down. The organization can fit its budget based on its requirements, so you pay for what you need. The system has some disadvantages too, with, of course, advantages over-weighing disadvantages, which are manageable.

\subsection{Security of Information/Ownership Issue}

The questions that rises here is: who owns the information? Is it the organization which is paying for these services or it is the hosting vendor? Based on the importance of the information saved in the cloud comes the importance of securing it. Therefore, the organization, should seek to save its information with the most reliable hosting service provider or vendor.

\subsection{Attacks}

As information is no longer being saved in the organization, the organization might be vulnerable to external attacks and threats over the Internet.

\section{The Case Study of UAE}

In the light of the above, this study is a case study of the application of CC for connecting three premier higher educational institution in the United Arab Emirates UAE, with a fast-developing economy and which is an educational developing economy and which is an educational hub of the Arab World.

The United Arab Emirates is a union of seven Emirates, which was found in 1971 to be a model Arab state in all respects, by its foresighted founding fathers. The UAE's is a well digitalized economy. Among other things, the UAE is noted for world-class higher educational institution with international staff, as well as students. 


\subsection{Objectives}

1) to resolve the problem of lack of communication between the three important public higher education institutions and also between them and the National Admissions \& Placement Office (NAPO) in the United Arab Emirates (UAE),

2) to find out the best means of $\mathrm{CC}$ for the inter-institutional communication and coordination,

3) to bring out the benefits of CC platforms, and

4) to draw policy conclusions and recommendations.

The institutional sample involved the three institutions are the Higher Colleges of Technology (HCT), UAE University, Zayed University (ZU) and the NAPO that enables them to complete their joint tasks.

Obviously, the need for coordination and mutual communication among the IHEs needs no over-emphasis. For example, when a high school student fills out a NAPO application and makes his/her choice among the above-mentioned three UAE higher education institutions, NAPO formally enters the data and sends the applications to the respective institutions. However, the journey of student's record stops at each university/college. When a student who studies in one institution like UAEU and decides to transfer to HCT, at a later stage, a real communication problem arises between academic services departments. The problem occurs when attempting to process his/her transfer, along with admission and enrolment requirements, and approving course equivalencies, where the student has to go back and forth to seek approvals and provides most of the documents.

Another issue concerning the student's record is that the receiving institution has to clarify the academic status of the student in terms of dismissal, warnings and academic probations, which means that NAPO has to go through long time-consuming procedures. Therefore, it can be clearly seen that, in the whole process, there is a lack of a shared collaborative system between the three institutions that hold students' records. Therefore, there is a pressing need to establish a common collaborative system joining the three institutions with each other and also with the NAPO.

\subsection{Magnitude of the Problem}

The above-mentioned lack of communication is considered to be a serious problem, due to the following reasons:

- Considerable waste in time, efforts, and resources for all parties.

- Different application formats are being used by the three institutions, causing pointless duplication that adds to the student's frustration and dissatisfaction with the service.

- Delay in automating the process between the three higher education institutions.

- Miscommunication problems as the relevant departments are not communicating directly with each other. 
- Storage space which is considered as a problem when it comes to the physical files in each institution, which is also environmentally unfriendly.

- Risk of losing or misplacing documents due to having hard copies stored in various locations.

\section{Research Design and Methodology}

To achieve the study objectives, a sample of respondents was drawn from the select institutions and four questionnaires were addressed for relevant information by direct interview method. The three researchers had taken due care in the choice of the IHEs, sample of respondents, questionnaires and in getting the questionnaires filled by direct interview method, to get hold of correct information and a true picture of the situation of non-cloud computing, and to determine the benefits of the introduction cloud computing method (CCM).

\subsection{Select Institutions}

The application of cloud computing technology to the institutions of higher education viz. colleges and universities in the educationally rising United Arab Emirates (UAE), with global faculty and students, is gone into with a sample of 3 IHEs, given below.

\begin{tabular}{lcccc}
\hline \multicolumn{4}{c}{ Comparison of UAE Institutions } \\
\hline \multicolumn{1}{c}{ Name of Institution } & $\begin{array}{c}\text { Year of } \\
\text { Establishment }\end{array}$ & $\begin{array}{c}\text { Student } \\
\text { Strength }\end{array}$ & $\begin{array}{c}\text { UAE } \\
\text { Ranking }\end{array}$ & $\begin{array}{c}\text { World University } \\
\text { Ranking }\end{array}$ \\
\hline $\begin{array}{l}\text { Zayed University, Abu Dhabi, Alain, } \\
\text { Dubai }\end{array}$ & 1998 & 9250 & 4 & 2503 \\
$\begin{array}{l}\text { UAE University, Alain, Abu Dhabi } \\
\text { Higher Colleges of Technology }\end{array}$ & 1976 & 14,000 & 1 & 1139 \\
\hline
\end{tabular}

Source: Ranking Web of Universities, Retrieved on 24 November, 2018 from: http://www.webometrics.info/en/Asia/United\%20Arab\%20Emirates\%20.

The students refer to the year of this study, which was carried out in the months January-March, 2018.

\subsection{Interview Design}

Four types of questionnaires were designed for the interviewees' (See Appendixes A-D). The first Questionnaire (Appendix A) was designed to be often open ended questions. The second and Third Questionnaires (Appendix B and Appendix C) were designed to be of four open ended questions each. The fourth Questionnaire (Appendix D) was designed to be of five open ended questions. Interviews were done face-to-face (HCT, STD) and via phone with partial and email (ZU, UAEU, HCT, NAPO).

\subsection{Respondent Sample}

The sampling technique used in this research was focused mainly on academic 
services employees (officers, senior officer and supervisors) in the three institutions, NAPO supervisor, HCT Head of Enterprise System Development and one student of engineering studying in Ras Al Khaimah Higher College of Technology. A sample of 6 interviewees was selected to capture their perceptions on how can Enterprise Cloud Computing Technology solve the problem of miscommunication between the three higher education institutions and to consider the important factors needed when implementing such a technology. The interviews were arranged by setting an appointment with interviewees via email to find appropriate time to meet and samples of questions were sent to them in advance. The sample of respondents/interviews was the following.

1) Higher College of Technology (HCT)

Acadmic Service Senior Officer/Ras Al Khaimah Higher Colleges of Technology.

Head of Enterprise System Development/Abu Dhabi Central Services (CS).

Engineering Student at Ras Al Khaimah Higher Colleges of Technology. (STD).

2) United Arab Emirates University (UAEU)

Manager, Students Recruitment/Al Ain

3) National Admissions and Placement Office (NAPO)

Supervisor-Application \& DP

4) Zayed University (ZU)

Admission Officer/Dubai

\subsection{Respondent Responses}

Interviewees were asked whether their students database was connected with other higher education institutions, (see Appendix A-Question 1). A similar question was asked to interviewees if there is any common enterprise system used among the three institutions, (see Appendix B and Appendix C-Question 1). Respondents totally agreed that currently there was no common enterprise system shared among the three institutions in order to communicate students' records (Table 1).

Participants were asked, how easy it is to transfer students to other college/university? (see Appendix A-Question 2), a similar question was asked to the student to describe the transfer experience, (see Appendix D-Question 4). As shown in Table 2, three interviewees agreed that it takes a long time which delays students admission, whereas two of them agreed that students need to check with the other institution regarding the status of transfer. Finally, three interviewees indicated that most of the transfers were done through NAPO.

Respondents were asked about the student transfer process (see Appendix A, Appendix C and Appendix D-Question 3), as shown below, the student transfer process is summarized in Table 3.

Interviewees were asked, how long does it take to complete the process of transfer? (see Appendix A-Question 4). A similar question was asked to the student, (see Appendix C and D-Question 2), as shown in Table 4, all 
Table 1. Student database.

\begin{tabular}{ccc}
\hline Category label & Interviewee response & Respondents \\
\hline Database connectivity & No & ZU, UAEU, HCT, CS, NAPO \\
\hline
\end{tabular}

Table 2. Ease of transfer.

\begin{tabular}{llc}
\hline Category label & \multicolumn{1}{c}{ Interviewees' response } & \multicolumn{1}{c}{ Respondents } \\
\hline \multirow{3}{*}{ Student Transfer } & $\begin{array}{l}\text { Takes longer time, delays student admission } \\
\text { Student needs to check with other institution } \\
\text { regarding the transfer } \\
\text { Most of the transfers are done through NAPO }\end{array}$ & $\begin{array}{c}\text { ZU, UAEU and STD } \\
\text { UAEU and STD }\end{array}$ \\
\hline
\end{tabular}

Table 3. Student transfer process.

\begin{tabular}{llc}
\hline Category label & \multicolumn{1}{c}{ Interviewees' responses } & Respondents \\
\hline & $\begin{array}{l}\text { 1) Student checks place availability with the receiving } \\
\text { institution and checks transfer requirements. }\end{array}$ & \\
2) Official Transcript is requested by receiving institution & \\
3) Students withdraw form from pervious institution and & \\
take transcript to receiving institution & ZU, UAEUU, \\
Transfer Process & 4) Receiving institution check with NAPO regarding & HCT, NAPO \\
& academic status & \\
& 5) Once academic status is cleared, NAPO upload student \\
& record in their banner and creates a new student number \\
& 6) Receiving institution makes course equivalency if needed \\
and admits student to the right semester. & \\
\hline
\end{tabular}

Table 4. Transfer process period.

\begin{tabular}{ccc}
\hline Category label & Interview themes & Respondents \\
\hline Transfer Period & 2 to 3 weeks & ZU, UAEU, HCT, NAPO and STD \\
\hline
\end{tabular}

of the interviewees agreed that it takes 2 to 3 weeks to complete the process of transferring the student from one institution to another.

Interviewees were asked in Appendix A, Appendix C and Appendix D-Question 5, if it is better to have one common student record system shared with other higher education institutions. As shown in Table 5, four interviewees (ZU, UAEU, NAPO and STD) agreed that it would be good to have a common students record system to save time and effort and three interviewees (ZU, UAEU and NAPO) agreed that such a system would save efforts for both students and employees and it would simplify the process. In addition, it would be easy to access students record and check their information and it would eliminate complication with transfer and extra steps to be done.

Participants were asked regarding the current issues they faced when admitting students transferred from other higher education institutions (see Appendix A-Question 6) and (Appendix C-Question 4). As shown in Table 6 below, two of the interviewees ( $\mathrm{ZU}$ and HCT) agreed that the main issues were longer time consumed because there was no direct involvement or connection 
Table 5. Usefulness of shared student record system among all higher education institutions.

\begin{tabular}{clc}
\hline \multicolumn{1}{c}{ Category label } & \multicolumn{1}{c}{ Interview themes } & \multicolumn{1}{c}{ Respondents } \\
\hline & Saves time & Saves effort \\
& Simplifies the process & ZU, UAEU, NAPO and STD \\
Sharing Student Record & Easy to access record and check \\
System & information & HCT, NAPO and STD \\
& No complications with transfer \\
& Eliminate extra steps done & HCT, NAPO and STD \\
& & \\
& & \\
\hline
\end{tabular}

Table 6. Main issues institution faced when admitting transferred student.

\begin{tabular}{llc}
\hline Category label & \multicolumn{1}{c}{ Interview themes } & Respondents \\
\hline & $\begin{array}{l}\text { Longer time consumed because there is no direct involvement } \\
\text { or connection between all Higher education institutions. } \\
\text { Delay on receiving student official transcript. } \\
\text { Some students are unable to go to Abu Dhabi to sign the }\end{array}$ & ZU and HCT \\
& $\begin{array}{l}\text { Uithdrawal form and bring it to receiving institution. } \\
\text { Longer time to reply to emails between NAPO and other }\end{array}$ & HCT \\
& $\begin{array}{l}\text { Higher Education Institutions. } \\
\text { Difficulties to establish equivalencies of courses. } \\
\text { Longer time consumed to download student record in banner } \\
\text { system in receiving institution. } \\
\text { Student records is not updated on NAPO site after students } \\
\text { are admitted to any Higher Institution. }\end{array}$ & HCT \\
& HCT \\
\end{tabular}

between all higher education institutions. One interviewee (UAEU) highlighted is the delay on receiving student's official transcripts, and another interviewee (HCT) indicated some student's inability to go to Abu Dhabi to sign the withdrawal forms and bring them back to the receiving institution, and also long time taken to reply to emails between NAPO and other institutions. Furthermore, there were some difficulties to establish equivalencies of courses and it took longer time to download students records in banner system at the receiving institution. Finally, NAPO indicated that the student records were not updated on NAPO site after the admission of students to any Higher Institution.

The participants were asked if they were familiar with Enterprise Cloud Computing or not (see Appendix A-Question 7), (Appendix B-Question 2) and (Appendix C-Question 6). As shown in Table 7 below, one respondent (CS) was actually using it in their system for HCT curriculum management system and curriccNet. Similarly, all students' mailboxes were on cloud using Microsoft Office 365. Whereas, two of the respondents indicated their ignorance of the system and two of the interviewees had basic knowledge about Cloud Computing.

Participants were also asked regarding how useful do they think using Enterprise Cloud Computing would be and what advantages it would bring them (see Appendix A-Question 8) and (question 4 in-Appendix B). As shown in Table 8 below, one interviewee agreed that would be useful to share student's information between all higher education institutions, and students would not be 
Table 7. Knowledge about enterprise cloud computing.

\begin{tabular}{ccc}
\hline Category label & Interview themes & Respondents \\
\hline & Are actually using it & CS \\
Knowledge about Enterprise & Have heard about it & ZU, NAPO \\
Cloud Computing & Basic knowledge & UAEU \\
& Not really & HCT \\
\hline
\end{tabular}

Table 8. Usefulness of enterprise cloud computing.

\begin{tabular}{llc}
\hline Category label & \multicolumn{1}{c}{ Interview themes } & Respondents \\
\hline & $\begin{array}{l}\text { Saves time, efforts and money } \\
\text { Not useful if it is not secure } \\
\text { As heard from researcher, useful to share student } \\
\text { information among all institutions. }\end{array}$ & ZU \\
Usefulness & HCT \\
& $\begin{array}{l}\text { As heard from researcher, student will not be asked to go to } \\
\text { Abu Dhabi to sign the withdrawal form and bring it to } \\
\text { receiving institution } \\
\text { No maintenance cost, smaller investment, backup, disaster } \\
\text { recovery }\end{array}$ & HCT \\
\hline
\end{tabular}

asked to go to Abu Dhabi to sign the withdrawal forms and bring them back to the receiving institution. Another interviewee thought that it would not be useful if it was not secure whereas, one interviewee indicated that it would save time, efforts and money.

The research participants were asked why Enterprise Cloud Computing was not applied in their organization, (see Appendix A-Question 9). A similar question was asked to other interviewees, if there were any plan to use Cloud Computing in the future, (see Appendix B-Question 4). As shown in Table 9 below, three interviewees (ZU, UAEU and HCT) indicated that they do not know, whereas, one interviewee (CS) indicated it was used in Higher Colleges of Technology in 2014 simply for storing critical logs and they were planning to use it from 2015 to share a point in Cloud.

Research respondents were asked regarding the type of information they would like to share it with other institutions, (see Appendix A-Question 10). As shown in Table 10 below, three interviewees (ZU, UAEU, and HCT) indicated that they would like to share students academic status and transcripts. Two interviewees (ZU and HCT) indicated that they would like to share special details needed about students. Finally, one interviewee (HCT) would like to share student attendance and teachers' comments.

The student was asked where was he transferred from? And he indicated that he was transferred from UAEU to HCT.

\section{Discussion}

Lakshminarayanan et al. [8] argued that the need for a technology like Cloud Computing is essential to support any education environment in many ways, especially in terms of communication and collaboration and research. The focus 
Table 9. Why enterprise cloud computing is not yet applied in each institution.

\begin{tabular}{clc}
\hline \multicolumn{1}{c}{ Category label } & \multicolumn{1}{c}{ Interview themes } & \multicolumn{1}{c}{ Respondents } \\
\hline & $\begin{array}{l}\text { Don't Know } \\
\text { It was used in HCT in 2014 for } \\
\text { storing critical logs } \\
\text { HCT was planning to use it in } \\
\text { 2015 for share point in Cloud }\end{array}$ & ZU, UAEU and HCT \\
CS
\end{tabular}

Table 10. Type of shared information.

\begin{tabular}{clc}
\hline Category label & \multicolumn{1}{c}{ Interview themes } & \multicolumn{1}{c}{ Respondents } \\
\hline & Student academic status & ZU, UAEU and HCT \\
Type of Shared & Student Transcript & ZU, UAEU and HCT \\
Information & Student attendance & HCT \\
& Teachers comments & HCT \\
& Special details needed about student & ZU and HCT \\
\hline
\end{tabular}

of the research is on one department which is the Academic Services of each institution and related parties such as NAPO and students as being the customers of these institutions. In order to investigate how Cloud Computing can be the best fit for these institutions and the factors that must be considered, six qualitative interviews were conducted. It was important to hear from the relevant people and ask them to explain how they performed things and what can he enhanced. The questions and the answers were grouped and categorized to be analyzed as follows:

As shown in Table 1, all participants stated that there was no common student system connecting the three institutions. This confirms the expectation of the researchers that there is no system connecting these higher education institutions. Having this answer, allowed the research to be carried out to introduce the technology of Cloud Computing to them. They argued that in today's world it is imperative to have the latest information technology to associate itself with education in all aspects to maximize the benefits for students and staff. Table 2 showed that all participants agreed that one of the negative effects of not having a common student data system is that the transferring process is not really easy as it is time consuming for both students and academic services staff. Students who are transferring can be highly affected as it may result in missing some classes because their transfer requirements are not completed yet. Cloud Computing in this term can be a big advantage in saving time and making the lives of all parties easier. According to [4] Cloud Computing would provide lots of flexibility to its users and can be personalized to serve their needs.

Table 3 highlighted the steps of the transferring process. The process was long and involved lots of people and many visits were needed to be made by the students. With Cloud Computing some of the steps can be eliminated and others can be minimized or automated. For example, the student does not have to physically visit the receiving institution to provide the withdrawal letter and check space availability as it can be viewed online and easily communicated be- 
tween the academic departments of both institutions. Another example, having a shared student system through Cloud Computing, would allow the receiving institution to check the academic status of the student which can speed the process and admit the student in less time. According to [9] the cloud approach allows everyone to view and work on the same information at the same time in a collaborative and dynamic manner. Table 4 emphasized the previous points as all participants expressed their dissatisfaction with the duration of the transferring process which took from 2 to 3 weeks. The researchers strongly believe that with the utilization of Information Technology, the transferring process should not take more than 1 hour maximum. The delay of 2 to 3 weeks means the student might miss some of his classes which would add a burden to the instructors at the receiving institution as they have to spend extra time with the student to enable him/her to catch up. Koba [10] argues that with the availability of a technology like Cloud Computing that is easy to deploy and requires less effort with more functionality, organizations that are not utilizing it will not be able to achieve competitive advantage.

Table 5 provided a clearer picture of how many participants accepted the idea of having a shared system and what they expect from it. Their responses were very positive and very much in congruence with what Cloud Computing can provide them with. In short, they were looking for a system that can save time and effort, and easy to use and improves the speed of the process. Michael King, IBM's vice president of global education industry Michael King argued that having technology like Cloud Computing in education will lead to high quality in terms of education resources and shared services [9]. [11] believed that Cloud Computing will soon replace the traditional IT system allowing more flexibility to users. Table 6 listed the issues faced by the participants who were involved in transferring students until they were officially admitted. The purpose of this question was to get specific and in-depth explanations regarding the practical issues they faced in the absence of a proper communication and the absence of a common student system. The participants mainly focused on issues like long time, delay, physical visits by students, no real-time information, more effort, extra and repeated steps. Here comes the importance of Cloud Computing that can solve these issues in more effective and efficient ways. Frantsvog et al. [11] emphasized that this technology brings lots of advantages to organizations and its users as would be able to process information and data faster than with the current traditional IT.

The results shown in Table 7 are not surprising as it was expected that participants have no or limited knowledge about Cloud Computing. Only 1 out of 5 showed full knowledge of this system and that was the Head of Enterprise System Development in Central Services (CS) at HCT. [4] support this point when they mentioned in their study that Cloud Computing "is considered new computing paradigm" which started to have a big attention by organizations around the world. As for the higher education institutions in this study, the lack of knowledge with Cloud Computing has important implications. Comprehensive 
and effective training is imperative and must be provided for the relevant employees.

Table 8 highlighted more dimensions of what participants think of Could Computing and how it would be useful in enhancing communication, especially when transferring students between their institutions. Answers revolved around saving time, cost, and effort of the academic services staff, students and all parties involved. They were also concerned about its security, which is a critical factor that needs consideration. This is exactly the point that the researches of this study are trying to reach, by making users provide their expectations and the senior management to understand the benefits their organizations will reap from Cloud Computing. What they have expected matched with the benefits that were stated by many researchers in previous studies. For example [8], states that Cloud Computing would maximize productivity and creativity, response to demand and changes quickly while managing expenses. [12] also listed some benefits such as cost effectiveness, easy deployment, more scalable solutions and functionality. Cloud Computing allows personalization according to organizations' needs and demands [9]. While [11] highlighted the benefits by arguing that it is scalable and fast to deploy which allows businesses to expand its IT provision when there is an increased requirement. It also saves too much of time, effort and resources which means doing more with less waste. Table 9 demonstrated that participants did not really know why Cloud Computing was not yet implemented in their organizations, except the Head of Enterprise System in CS of HCT, who stated that Cloud Computing was going to be implemented in the near future. This response was surprising to the researchers as they had not expected that there is a future plan to have this system which made their goal much easier to achieve.

Table 10 showed the type of information participants would like to share the most. All of the participants from the three institutions agreed on the importance of sharing student information like academic status, transcripts, attendance records and teacher comments. From these answers, it can be clearly noticed that the system should have the security factor which was mentioned in Table 8 earlier. This is considered to be one of the essential issues that need to be highlighted and supported by previous studies. According to [13] security is one of the serious factors that face Cloud Computing and it is considered to be a threat to its users as information might lose its confidentiality. The security factor is considered a challenge when organizations utilize Cloud Computing and it is the responsibility of the organizations to observe, manage and make sure that cloud providers keep the data in secure environment [4]. Security is considered to be a big issue as outsourcing data using this system could prove to be unsafe [11]. While [9] has a positive view of Cloud Computing in terms of security as he simply argued that if an institution is very much concerned about security issue, it should build its own private cloud services. In addition, there are many services providers who are trustworthy and have a good reputation in the market that organizations can deal with. For example, IBM provides some applications 
and software that are secure with cloud-based high performing environment [14].

There was a question shown in Other Questions part, Appendix D, represents a response from a student who transferred from UAEU to HCT. The researchers wanted to see the importance of having a shared student system from a customer's point of view which is in this case is the student. The intention was to interview more than one student, but because of the time limitation and as holiday season was approaching, one interview was conducted and it was useful as it confirmed the need for implementing Cloud Computing in the three higher education institutions. Thomas [9] emphasized that addressing customer's needs is what makes businesses run successfully.

\section{Conclusions}

The overall conclusion of the study is that the IHEs in the UAE are not presently cloud computing connected, but they would like to have this new computing system for inter-university connectivity and better student services, especially in migration from one university/college to another university/college, with care.

In the light of the above overall conclusion, some Recommendations, Suggestions are ventured.

1) For services and service organization(s), Platform as a service (PaaS) should be a good cloud computing option, as in the case of the three institutions because of:

a) The flexibility of this model to be customized.

b) Developers will take the responsibility of managing and modifying, testing and deploying the application based on the institutions requirements in a much quicker, simpler and cost-effective way.

c) A third party takes the responsibility to manage and virtualize servers, storage, networking and PaaS software itself.

d) It can be used as a hybrid model when there is a need for either public or private cloud in case of future expansion.

2) The three institutions can deploy a public cloud in a hosting vendor which takes care of the whole hardware infrastructure provided for the cloud. Scalability of the hardware will be based on the requirements coming from the three institutions based on their needs and growth. This means you can scale up or down based on the needs of that application and the recommendation coming from the institutions.

3) The facility can involve more IHEs in the Emirates, which is emerging as a global educational higher education centre.

4) Workshops need to be run to familiarize staff with the usefulness of Cloud Computing and its features and how to use it.

5) Trainings should be provided for the developers as, for example people from IT department.

6) Quality of service security, and confidentially of data can be managed 
through a Service Level Agreement (SLA) to be signed by the institutions and the third party.

It is expected that many employees in the involved institutions, studied will not embrace the introduction of the proposed technology wholeheartedly. Employees often resist change for various reasons. For many employees' their routine gives them a sense of security. Anything that disturbs the routine triggers fear of loss of control. This is particularly true of the proposed "change", in which way, questions their current knowledge. To them, knowledge is power, and anything that questions this knowledge may be perceived as loss of power/ control.

In any organization, people in general are critical of any big change in the established organizational practices. The fear of change in our particular case is fear of sudden incompetency. Some employees who have been working in these institutions for many years and perhaps were awarded for their competency at work might suddenly fear this change because they might lack the technical skills to deal with the proposed electronic system and, therefore, fear being labeled as incompetent. Argues that some employees might resist change because they lack technical skills to use and reap the benefits of new technology [15] [16]. Other reasons why some employees might be reluctant or even resist change are highlighted by [17], and the ones that might be relevant to our case are Loss of position, new responsibilities, and past experiences with previous changes.

It is the employees who make up organizations and they are the recipients and implementers of change. They are the ones who will either accept and adopt changes, or resent and oppose changes. If organizational change is to be effective and prosper their organizations, the employees must be prepared for such transformation. Change readiness does not happen automatically and it should not be underestimated. Misjudging the organizational and employees change readiness may result in managers spending significant time and effort trying to deal with employees' reaction to change [18].

No change will be realized effectively without first dealing with the reaction of employees to the change. In other words, employees should be convinced to change and made willing to change. Vakola, stated that "organizational change cannot be effectively implemented without change recipients' willingness to change themselves and support the suggested organizational change programme/initiative [19]. These changes cannot occur if employees are not ready for it". Change management and making specific recommendations on how to handle the proposed change is beyond the scope of this paper. However, it is important to mention here two essential issues, namely communication and training.

Insufficient or confusing communication is one of the main reasons for the failure of change efforts [20]. Communicating the rationale for the change and communicating clear messages creates, according to him common understanding, proactively addresses misunderstandings, and sustains efforts. The impor- 
tance of effective communication in developing changes readiness, gaining employee commitment, and diminishing uncertainty [21]. Chiang found that employees believed that communication was the best support managers could provide to them, followed by training related to the proposed change [22].

Frankly speaking, how can we expect employees to wholeheartedly embrace the proposed change without first promising them that they will receive the necessary training and coaching to enable them to work comfortably with the new system? The importance of effective training in providing employees with the confidence and the essential skills enables them to carry out their assigned duties [23]. In fact, the issue of 'training' in change management is not a new issue. The importance of training is the management's responsibility to provide employees with adequate training and education to enable them implement the change initiative successfully [24]. Therefore, it is clear that in order to implement this change successfully, the change should not be imposed on employees as orders. It is recommended that management should 'convince' employees to change rather than 'force' them to change. Of course, this would require a lot of effective communication. Training is another very important issue that must be kept in mind.

\section{Limitations}

This study is mainly a small sample study of the problem of application of cloud computing to 3 select higher educational institutions in the United Arab Emirates, for their collaborative functioning. As such, it is bound by the limitations of sample, data, time, etc., though it brings home the fact of the need for cloud computing on higher educational institution in the UAE. It is largely management based with under representation of students in respondent sample. A different sample (s) over a different period may bring in different results.

Hence, future research on the problem may take care of different geographic (areas), institutions and Efficiency aspect, etc.

\section{Acknowledgements}

We are grateful to those administrators at Higher Colleges of Technology, UAE University, Zayed University, and the National Admissions and Placement Office of the sample cooperation, in responding to questionnaires.

\section{Conflicts of Interest}

The authors declare no conflicts of interest regarding the publication of this paper.

\section{References}

[1] Hardy, Q. (2018) How Cloud Computing Is Changing Management. Harvard Business Review. https://hbr.org/2018/02/how-cloud-computing-is-changing-management 
[2] Winston, A. (2011) Cloud Computing Is Greener. Harvard Business Review. https://hbr.org/2011/03/cloud-computing-is-greener

[3] Bloom, N. and Pierri, N. (2018) Research: Cloud Computing Is Helping Smaller, and Newer Firms. Harvard Business Review.

https://hbr.org/2018/08/research-cloud-computing-is-helping-smaller-newer-firmscompete

[4] Grance, T. and Jansen, W. (2011) Guidelines on Security and Privacy in Public Cloud Computing. National Institution of Standards and Technology, US Department of Commerce.

https://www.nist.gov/publications/guidelines-security-and-privacy-public-cloud-co mputing

[5] Sultan, N. (2010) Cloud Computing for Education: A New Dawn? International Journal of Information Management, 30, 109-116.

https://doi.org/10.1016/j.ijinfomgt.2009.09.004

[6] Rouse, M. (2014) Search Cloud Computing. http://searchcloudcomputing.techtarget.com/definition/SPI-model

[7] Gartner Group (2013) Newsroom, October 24. http://www.gartner.com/newsroom/id/2613015

[8] Lakshminarayanan, R., Kumar, B. and Raju, M. (2013) Cloud Computing Benefits for Educational Institutions. Second International Conference of the Omani Society for Educational Technology, Oman. https://arxiv.org/abs/1305.2616

[9] Thomas, P.Y. (2011) Cloud Computing. The Electronic Library, 29, 214-224. https://doi.org/10.1108/02640471111125177

[10] Koba, M. (2011) Cloud Computing 101. https://www.cnbc.com/id/43077233

[11] Frantsvog, D., Seymour, T. and John, F. (2012) Cloud Computing. International Journal of Management \& Information Systems (Online), 16, 317-324. https://doi.org/10.19030/ijmis.v16i4.7308

[12] Mezghani, K. and Ayadi, F. (2016) Factors Explaining IS Managers Attitudes toward Cloud Computing Adoption. International Journal of Technology and Human Interaction (IJTHI), 12, 1-20. https://doi.org/10.4018/IJTHI.2016010101

[13] Armbrust, M., Fox, A., Stoica, I., Griffith, R., Joseph, A., Katz, R., Konwinski, A., Lee, G., Patterson, D., Rabkin, A., Stoica, I. and Zaharia, M. (2010) A View of Cloud Computing. Communications of the ACM, 53, 50-58.

https://cacm.acm.org/magazines/2010/4/81493-a-view-of-cloud-computing/fulltext https://doi.org/10.1145/1721654.1721672

[14] IBM (2014) BM SPSS Modeler Gold on Cloud. IBM Corporation Software Group, New York.

[15] Weeks, W., Roberts, J., Chonko, L. and Eli, J. (2004) Organizational Readiness for Change, Individual Fear of Change, and Sales Manager Performance: An Empirical Investigation. The Journal of Personal Selling and Sales Management, 24, 7-17. https://doi.org/10.1080/08853134.2004.10749012

[16] Wargin, J. and Dobiey, D. (2001) E-Business and Change: Managing the Change in the Digital Economy. Journal of Change Management, 2, 72-82.

[17] Bagranoff, N., Eighme, J. and Kahl Jr., H. (2002) Who Moved My Ledger? CPA Journal, 72, 22-26.

[18] Smith, I. (2005) Achieving Readiness for Organisational Change. Library Management, 26, 408-412. https://doi.org/10.1108/01435120510623764

[19] Vakola, M. (2013) Multilevel Readiness to Organizational Change: A Conceptual 
Approach. Journal of Change Management, 13, 96-109. https://doi.org/10.1080/14697017.2013.768436

[20] Heckelman, W. (2017) Five Critical Principles to Guide Organizational Change. $O D$ Practitioner, 49, 13-21.

http://wlhconsulting.com/wp-content/themes/wlh/pdf/ODP-Five\%20Critical\%20Pr inciples\%20to\%20Guide\%20Organizational\%20Change.pdf

[21] Simoes, P. and Esposito, M. (2014) Improving Change Management: How Communication Nature Influences Resistance to Change. Journal of Management Development, 33, 324-341. https://doi.org/10.1108/JMD-05-2012-0058

[22] Chiang, C.F. (2010) Perceived Organizational Change in the Hotel Industry: An Implication of Change Schema. International Journal of Hospitality Management, 29, 157-167. https://doi.org/10.1016/j.ijhm.2009.08.002

[23] Jorritsma, P.Y. and Wilderom, C. (2012) Failed Culture Change Aimed at More Service Provision: A Test of Three Agentic Factors. Journal of Organizational Change Management, 25, 364-391. https://doi.org/10.1108/09534811211228102

[24] Galpin, T. (1996) The Human Side of Change: A Practical Guide to Organizational Redesign. Jossey-Bass, San Francisco. 


\section{Appendix A}

\section{Interview Questions (ZU, UAEU, HCT)}

1) Is your student database connected with other universities?

2) How easy it is to transfer student to other college/university?

3) Can you explain the process?

4) How long it takes to complete the whole process of transferring a student?

5) Do you think it is better to have one student record system shared with other universities? 6) What are the current issues that you face when admitting student transferred from other university?

7) Do you know Enterprise Cloud Computing?

8) How useful do you think Enterprise Cloud Computing will be?

9) Why Enterprise Cloud Computing is not applied yet in your organization?

10) What type of information do you want it to be shared?

\section{Appendix B}

\section{Interview Questions (CS)}

1) Currently, is there a common enterprise system used among the three institutions to communicate with each other?

2) Do you know Enterprise Cloud Computing?

3) From your point of view, why HCT is not using Enterprise Cloud computing Technology?

4) Are there any plan to use Cloud computing in the future?

5) What advantages would Cloud Computing bring to HCT?

\section{Appendix C}

\section{Interview Questions (NAPO)}

1) Currently, is there a common enterprise system used among the three institutions to communicate with each other?

2) How long it takes to transfer a student between institutions?

3) Why it takes long time?

4) As far as I know that after student is admitted to any college, his information is not updated on NAPO site? Is that correct?

5) Isn't it better to have a common system like cloud computing for universities to deal with each other?

6) Do you know Enterprise Cloud Computing?

\section{Appendix D}

\section{Interview Questions (STD)}

1) From where have you transferred?

2) How long it took you to transfer

3) How easy was the process?

4) How do you describe the transferring experience?

5) Do you have any recommendation? 